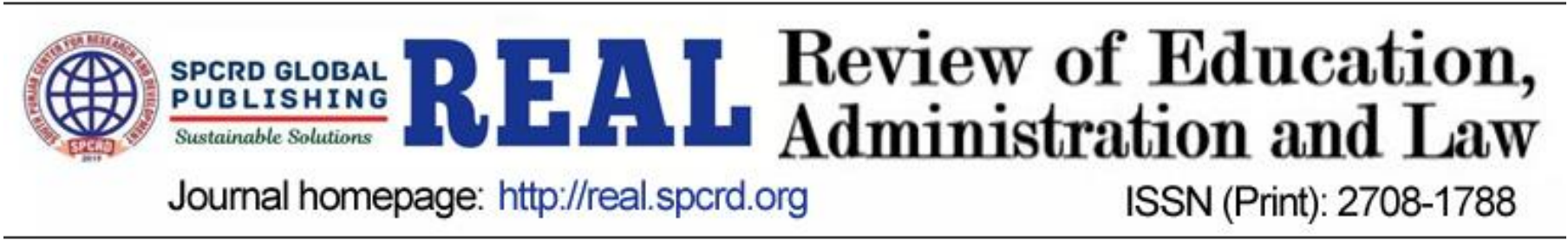

\title{
Perceived Usage and Benefits of Metacognitive Strategies by University Students
}

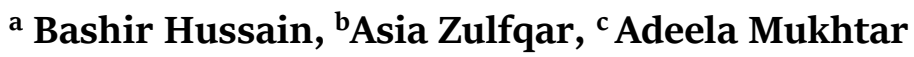

a Assistant Professor, Department of Education, Bahauddin Zakariya University, Multan, Pakistan: bashirhussain@bzu.edu.pk b Assistant Professor, Department of Education, Bahauddin Zakariya University, Multan, Pakistan.

c M. Phil. Scholar, Department of Education, Bahauddin Zakariya University, Multan, Pakistan: amalvio5@gmail.com

Corresponding author's email address: bashirhussain@bzu.edu.pk

\begin{tabular}{l} 
ARTICLE DETAILS \\
\hline History: \\
Accepted 25 October 2018 \\
Available online 31 December \\
2018
\end{tabular}

\section{Keywords:}

Metacognition, Metacognitive

Strategies, University, Students

JEL Classification:

P36, L12, L19

DOI: $10.47067 /$ real.v1i1.1

\section{ABSTRACT}

Currently, the use of metacognitive strategies by students is highly being encouraged for their effective learning. Metacognitive strategies are those learning devices which become learners' need for their optimal learning. Likewise, metacognitive strategies enable learners to become more confident, skillful, self-evaluator, and more independent by managing and directing their learning process at their own in the best way. Considering the benefits of using metacognitive strategies for students, the theme has not been qualitatively explored about the use of strategies by the students in universities of Pakistan. The purpose of this research work is to explore the perceived use, the extent of use, and benefits of metacognitive strategies by university students in Multan City. Survey research design was used for the accomplishment of the objectives. All students of three public sector universities of Multan city were selected as population. Qualitative data were analyzed through content analysis. The process started by tracing themes, followed by calculation of frequencies and percentages of students' opinions to explore the frequency of use, extent of use, benefits, and awareness about using metacognitive strategies by university students. For calculation of frequencies and percentages, basic statistics was used. The results found that summarization, highlighting, note taking, bulleting and the concept mapping are the most frequently used learning strategies by university students. It was further found that most of the students use metacognitive strategies during exams, quizzes and tests, but their learning process was improved by using metacognitive strategies. It was recommended for the teachers to promote usage of group learning, discussion method and book reading habits among students and for the policy makers and teachers to create awareness about the frequent use, benefits and importance of metacognitive strategies in the improvement of university students' learning. 
(C) 2018 The authors. Published by SPCRD Global Publishing. This is an open access article under the Creative Commons Attribution-

NonCommercial 4.0

\section{Introduction}

Metacognition is an extremely powerful tool for students' learning. Metacognition is defined as knowledge or cognition about how to learn (Slavin, 2009). Metacognition is "thinking about thinking" (Almasi, 2003; Hunt, 2006). Kuhn and Dean (2004) stated that metacognition is the process to provide an awareness to manage learner's own thoughts. In addition, metacognition includes learners' knowledge and awareness about their own cognitive activities (Schoenfeld, 1992; Sukarnan, 2005). Martinez (2006) viewed metacognition as a process of monitoring to control one's thoughts. The term metacognition provides awareness about the necessity to use learning strategies i.e. to plan, monitor, to manage and evaluate information (Efklides, 2011; Papaleontiou-Louca, 2014). O'Neil and Brown (1997) explained metacognition as the thinking about thinking, as it builds metacognitive strategy for the solution of learners' problems in their learning process. As metacognitive strategies enable learners to improve their awareness about thinking and the process of learning, and consequently enable learners for planning, monitoring and evaluating what they have learnt.

Metacognition has become an extremely powerful tool for students' learning (Veenman, Van HoutWolters \& Afflerbach, 2006). Metacognition refers to as "learning to learn" (Seyf, 2007). Metacognition enables a learner to apply a particular learning strategy for particular problem in a same but another new context by retrieving and deploying that learning strategy (Kuhn \& Dean, 2004). It provides ability of self-assessment to the learners whether they are using effective metacognitive strategy to solve the problem or not.

Metacognitive strategies spark learners' thinking for learning (Anderson, 1991) and for better performance. Based on prior research and being pioneer in this area, Anderson (1991) has given five core components of metacognition. The first component of metacognition is planning and preparation for learning. It includes students' thinking about goals and objectives of the study. Selection of clear and accurate objectives enables learners to become aware about the progress to achieve ultimate goal. Second component is selection and usage of learning strategies. This refers to learners' metacognitive capability to use and choose specific strategies in a situation. Learners must know about how to choose effective metacognitive strategy and when to use it according to the situation (Anderson, 1991).

Third component of metacognition is the monitoring of used strategy. Monitoring of the use of metacognitive strategies provides more chances for success to attain learning goals (Anderson, 1991). Once learners have selected a learning strategy, they need to check periodically whether this strategy has been effective or not and fulfils the purpose. If it is not, then they need to go back to change or modify the strategy according to situation. Next component of metacognition is coordinating among various strategies. To use metacognitive strategies in combined and an orchestrated mode is an essential metacognitive skill. Desoete and Veenman (2006) concluded that successful learners use cluster of metacognitive strategies at a time, in this way strategies work effectively (Derry, 1992). Gama (2000) explained successful learners enable to describe that why they use and implement the cluster of metacognitive strategies. The final component of metacognition is evaluating the effectiveness of strategy through many techniques. Through evaluation, learner can reflect the whole process about the application of learning strategies from start to end.

Metacognitive strategies are set of higher order decision-making skills, actions, beliefs, plans, and 
devices, which facilitate the learner to understand, store and retrieve to use the information or knowledge (O'Malley \& Chamot, 1990). Metacognitive strategies are viewed as decisions made by the learners before, during, and after their learning processes (Boekaerts, 1999). Rubin (2005) stated that metacognitive strategies are those strategies which control or regulate the cognitive strategies because cognitive strategies just assist a learner to achieve a particular goal of study but metacognitive strategies ensures learner to achieve particular goal through process of planning, monitoring, and evaluation. McCormick (2003) view cognitive strategies as the task achievement facilitator and metacognitive strategies as task achievement regulator. These strategies make the learners self-directed and enable them to solve their problems in the learning process easily (Azevedo \& Aleven, 2013).

Metacognition strategies are more proficient and significant than other strategies in the process of learning because once students are able to regulate their learning, they can use metacognitive strategy (Anderson, 1991). Hacker (2009) stated that metacognition allows learners to control their own learning. Metacognition includes awareness about learning, an evaluation of learners' needs related to learning process, and implementing and generating strategies. Herrera, Holmes and Kavimandan (2011) explained the application of metacognitive strategies in learning, for example, as self-monitoring support to develop self-learner who has the capability to plan for his/her studies for coming learning periods. This ability provides the skill of self-guidance to the learner throughout life by providing learning experience. This learning experience enable the learner are to gain higher order problem-solving skills in the learning process.

Although several strategies of metacognitive exist, but planning, monitoring and evaluation are the basic (Spörer \& Brunstein, 2006). Planning strategies includes goal the setting, selection of adequate learning strategy, and distribution of personal resources i.e., time and effort to achieve study goal (Zareei, 2007). Monitoring strategies includes awareness about the comprehension and performance of task to get feedback. Evaluation refers to the correction and modifications of learning plans and problems through reflective judgement (Boekaerts, 1999). There are some other metacognitive strategies, with brief explanation in different research studies, to improve students' learning. For example, elaboration strategies, presented by Ormrod (1999), includes summarization, paraphrasing and note taking to improve learning by encoding new information in learner's existing knowledge. Summarizing is an adequate learning strategy which includes brief representation of important information and outlining is representation of important points in hierarchical form.

Organization strategies of metacognition includes outlining, diagramming, drawing charts or tables, taking key ideas and making interconnections (Somuncuoglu \& Yilidirim, 1999). These strategies help to determine relationships between different ideas and presenting information in different modes for better understanding. Think aloud is a strategy that enhances students' capacities to think and process information, engage the students to self-stimulate their mental processing and to know leaners' own capability to comprehend study material, to ask questions about text, giving voice to self and others thoughts by asking question and purposeful reflection (Martinez, 2006). Smith, Rook and Smith (2007) stated that another metacognitive strategy is to write journal, in which students write down their perspectives about what they have learnt, and feedback related to metacognitive strategy which they have used. Other powerful strategy is self-questioning, as it helps learners in interpreting, synthesizing, analyzing, and evaluating study material. Killen (2000) favored strategy of cooperative or group learning. Cooperative learning has strong effects on learning than individual learning (Johnson \& Johnson, 2002).

Considering the significant role of metacognitive strategies in enhancing students' learning, it is 
important to explore its use by students and benefits from their perspectives. Metacognitive strategies are significant to enhance students' learning process, but university students are not fully aware about the uses and the benefits of metacognitive strategies in their learning process (Chutichaiwirath \& Sitthitikul, 2017; Novak, 2010), as found internationally. In Pakistan, it is also important to explore the usage and benefits of metacognitive strategies qualitatively from the perspective of university students. This research, therefore, explore the perceived use and benefits of metacognitive strategies by university students. This research further explores the extent and frequency of the use of metacognitive strategies by university students. Finally, this research also explores the students' level of awareness about the use of metacognitive strategies in three universities of Multan city.

\section{Objectives of Study}

This research article mainly explores the perceived use and benefits of metacognitive strategies of university students. Key objectives of this research were as follows:

- To explore the frequency of the use of metacognitive strategies by students of three universities of Multan City.

- To explore the extent of the use of metacognitive strategies by students of three universities of Multan City.

- To explore the benefits of the use of metacognitive strategies from the perspective of students of three universities of Multan City.

- To explore the students' level of awareness about the use of metacognitive strategies in three universities of Multan city.

\section{Research Methodology}

2.1 Research Design, Population and Sample

This research study used qualitative survey design, comprising a set of open-ended questions, followed by semi-structured interviews and group discussion. All the students from three public sector universities of the Multan city were selected as population of this research study. These three universities include large size Bahauddin Zakariya University, and medium size Women University, and Multan campus of University of Education. Sample of this research comprised 1011 students from three universities of Multan to collect their views about the perceived use and benefits of metacognitive strategies. For this purpose, both cluster and purposive sampling techniques were used for identification of the sample.

\subsection{Research Tool, Data Collection and Analysis}

Three tools were used for the collection of data in this qualitative study. First, a set of six openended questions was developed by researchers about use, extent, and benefits of metacognitive strategies as perceived by the students. This set of open-ended questions was administered to a sample of 1011 students in three universities, using cluster sampling technique. Although, all the students not responded to each of the six open-ended questions, most of the questions were answered by them. Second, semistructured interviews of 27 individual students were done by researchers and group discussion. Finally, three group discussions were also conducted, one from each university. The purpose of both semistructured interviews and group discussion was to seek opinions from students about the use, extent and benefits of metacognitive strategies as perceived by them. The validity of all three tools was guided through experts' opinions and the literature. The reliability was determined through inter-rater reliability method. 
For analysis of data obtained from all three tools, content analysis was used. Content analysis is systematic process of coding and finding themes (Hsieh \& Shannon, 2005). It is a research technique to determine valid interpretations from texts by describing and quantifying specific phenomena (DowneWambolt, 1992; Krippendorff, 2004). In this study, data were analyzed by making themes, calculating frequencies, and percentages of themes, in four sections related to frequency of use, extent of use, benefits and awareness about the use metacognitive strategies by university students.

\section{Results}

The results have been presented in four sections in response to objectives, related to frequency of use (high, moderate and least use), extent, benefits and awareness about use of metacognitive strategies by university students.

\subsection{Frequency of the Use of Metacognitive Strategies by Students}

This section presents the analysis of high, moderate and least use of metacognitive strategies by university students in their learning process. Each use has presented in a separate table given below. Table 1 presents the results related to 'highly used metacognitive strategies' by students, by calculating frequencies and percentages of students' opinions.

Table 1: Highly used metacognitive strategies

\begin{tabular}{|l|l|l|l|}
\hline $\begin{array}{l}\text { S. } \\
\text { No. }\end{array}$ & Themes & Frequency & Percentage \\
\hline 1 & Making summary, taking main idea. & 200 & $20 \%$ \\
\hline 2 & Highlighting, bolding the important terms. & 185 & $18 \%$ \\
\hline 3 & Notes taking, making self- notes. & 185 & $18 \%$ \\
\hline 4 & Making bullets, key points. & 173 & $17 \%$ \\
\hline 5 & Using/reading notes provided by teachers. & 164 & $16 \%$ \\
\hline 6 & Write down after verbal learning. & 140 & $14 \%$ \\
\hline 7 & Memorization, recall. & 135 & $13 \%$ \\
\hline 8 & Diagramming, sketching, concept map, flow charts. & 125 & $12 \%$ \\
\hline
\end{tabular}

Table 1 shows the list of frequently used metacognitive strategies by the university students for better learning. It indicates that the most frequently used leaning strategy is to summarize and taking main idea of the study material or topic, showing $20 \%$ use by university students. The use of highlighting and bolding the important terms is $18 \%$. Likewise, notes taking or making self- notes by university students is also $18 \%$. Table indicates that $17 \%$ students claim that they make bullets, main points or key points of the study material, $16 \%$ university students use notes provided by their teachers, $14 \%$ students claim that they write down the study material after verbal learning or memorization, $13 \%$ memorize the learning material, and $12 \%$ students claim that they use diagramming, sketching, concept mapping, flow charts for better learning.

Some responses of students about highly used strategies are cited for examples. One respondent stated: "I use summarization strategy to cope with the information or problem." One student responded as: "I make points or bullets to remember easily, then I make self-notes by using tree diagram. These notes help me to understand and remember topic for long period." The other student stated as: "First I understand the concept properly, then write down to remember it easily in short time, it helps me a lot in exams preparation. Sometimes, I also cram the topics." Table 2 presents the moderately used 
metacognitive learning strategies, by calculating frequencies and percentages.

Table 2: Moderately used metacognitive strategies

\begin{tabular}{|l|l|l|l|}
\hline $\begin{array}{l}\text { S. } \\
\text { No. }\end{array}$ & Themes & Frequency & Percentage \\
\hline 1 & Underlining important points. & 105 & $10 \%$ \\
\hline 2 & Making outlines. & 104 & $10 \%$ \\
\hline 3 & Use of example. & 85 & $8 \%$ \\
\hline 4 & Reading topic many times. & 85 & $8 \%$ \\
\hline 5 & Use of dictionary, meaning and translating. & 85 & $8 \%$ \\
\hline 6 & Self-questioning. & 70 & $7 \%$ \\
\hline 7 & Making heading, making sub-topics. & 70 & $7 \%$ \\
\hline 8 & Paraphrasing, rephrasing. & 65 & $6 \%$ \\
\hline 9 & $\begin{array}{l}\text { Using internet, searching, watching } \\
\text { videos/lectures. }\end{array}$ & 47 & $5 \%$ \\
\hline 10 & Relate topic with previous knowledge. & 42 & $4 \%$ \\
\hline
\end{tabular}

The table 2 shows that 10\% students are making outlines and underlined the important points or terms, $8 \%$ students use dictionary for meaning and translation of difficult terms, use daily life examples and reading a topic or study material many times for better understanding, $7 \%$ students making heading to break the lengthy topic into sub-headings and evaluate or monitor themselves through selfquestioning, $6 \%$ students paraphrase or rephrase the study material to learn easily. Table shows that 5\% university students use internet to search their study material, watch videos and listen lectures to clear their concepts for effective learning, $4 \%$ students relate their present knowledge of study material with prior knowledge to determine their relationship or linkage with basic and previous concepts or knowledge.

Some responses of university students, obtained through several interviews about moderately used strategies, are being cited here. One student respondent stated: "I use different learning strategies. Firstly I read study material many time to understand the concept, then underline the important information to learn easily. Lectures from internet gives me sufficient knowledge to clear my concept." Other student described it as: "I make specific points and then describe it in my own way. I use dictionary it helps me a lot to understand important terms and their meanings. Sometimes, I use example and try to highlight important questions first." Table 3 presents the least used metacognitive learning strategies by university students, by calculating frequencies and percentages.

Table 3: Least used metacognitive strategies

\begin{tabular}{|l|l|l|l|}
\hline $\begin{array}{l}\text { S. } \\
\text { No. }\end{array}$ & Themes & Frequency & Average \\
\hline 1 & Discussion, group learning & 25 & $2 \%$ \\
\hline 2 & Book reading as supplementary material & 25 & $2 \%$ \\
\hline 3 & Skimming and scanning & 25 & $2 \%$ \\
\hline
\end{tabular}

Table 3 indicates that only $2 \%$ students claim that they learn better through discussion and the 
group study with their peers. Similarly, 2\% students read books and use skimming and scanning method to understand the concept or idea. This minimum percentage indicates the least use of discussion method and less habits of book reading among university students. Two university students responded about the least used metacognitive strategies in their interviews are cited here. One respondent stated: "I use skimming and scanning method to read and understand a study material. This learning strategy saves my time." Another respondent shared his learning experience as: "I use simple and basic method to learn in an easy way, which is group learning. Through this method, I understand the concept by getting different point of views." The next section presents the analysis of results about the extent of the use of metacognitive strategies by university students in their learning process.

\subsection{Extent to Use Metacognitive Strategies by University Students}

This section examines the extent of the use of metacognitive strategies by university students in their learning, and Table 1 presents the results by calculating frequencies and percentages of students' opinions.

Table 4: Extent to use metacognitive strategies by university students

\begin{tabular}{llll}
\hline S. & Themes & Frequency & Average \\
No. & & & \\
\hline 1 & Yes, I use strategies. & 96 & $9 \%$ \\
2 & Using strategies to some extent. & 103 & $10 \%$ \\
3 & Using strategies every time while learning. & 113 & $11 \%$ \\
4 & Using strategies only in exams, quiz and tests. & 204 & $20 \%$ \\
5 & Student's not using strategies. & 495 & $49 \%$ \\
\hline
\end{tabular}

Table 4 indicates that only $9 \%$ students use strategies but they didn't mention the extent of use of strategies when they use, rather $10 \%$ students claim that they use these strategies more often or sometime in their studies and $11 \%$ students claim that they use learning strategies every time while learning anything. But 20\% students claim that they use these different learning strategies just during and near to their exams, quizzes or tests otherwise they don't use them. Table shows that $49 \%$ means near to half of the university students' not using different learning strategies, it means they have no awareness about the importance and benefits of metacognitive strategies in learning process or academic success. Some responses of the university students, collected through interviews, about the extent to use metacognitive strategies are being quoted here: One student stated as "I use different learning strategies for assignments, for quiz and short term exams for better preparation”. Other student responded as: "I use learning strategies every time when I learn something". One student stated that "I use different learning strategies often, especially when I need to use”.

\subsection{Perceived Benefits of the use of metacognitive strategies by students}

To examine student's perception and opinion related to the benefits of metacognitive strategies in their learning process, either their learning process improve or not based on their learning experiences, frequencies and percentages were calculated, and results are presented in Table 5.

Table 5: Benefits of the use of metacognitive strategies by university students

\begin{tabular}{llll}
\hline S. & Themes & Frequency & Average \\
No. & & & \\
\hline 1 & Better learning by using different learning strategies. & 735 & $73 \%$
\end{tabular}


2 Learning enhances but to some extent by these $185 \quad 18 \%$ strategies.

$3 \quad$ No improvement in Learning.

90

$9 \%$

Table 5 shows that most of the university students claim that the use of different metacognitive strategies enhances their learning, improve their weaknesses, solve their problems, improve their grades, achieving their study goals, and make their learning easier by saving their energy and time as well. The remaining $18 \%$ students perceive that there is little improvement in their learning by using different strategies and other 9\% claimed there is no enhancement in learning by using different learning strategies. It means these students either have not awareness about metacognitive practices even at university level or they are not aware about the right use of metacognitive strategies in learning process. Rather, $73 \%$ students claim that learning process improves by using different learning strategies. It means most of the students have awareness about the benefits of metacognitive strategies, either they used these strategies frequently or often, but they have positive responses about the benefits of different learning strategies. Some responses of students, obtained through interviews, about benefits of metacognitive strategies in their learning process were noted. One student responded as:

Yes, I use different strategies, obviously provide me sufficient knowledge to enhance learning. For example, method of making points is really helpful for me. It helps me to understand the things very quickly. I also understand the main idea of particular topic by using this method.

One student stated as: "Yes, learning strategies are very helpful in my studies. I don't use only one method but use different methods to achieve my goal." Another stated as: "Yes, these really enhance my learning and confidence as well. Especially, during exams." According to the point of view of another respondent, strategies provide help to some extent, as: "I think learning strategies provide help to some extent, because in our education system from primary level we focused on cramming rather than conceptual learning due to this students are not well aware about these strategies”.

\subsection{Awareness of Metacognitive Strategies by University Students}

To examine the awareness about the use and benefits of metacognitive strategies of university students, frequencies and percentages were calculated, and the results are presented in Table 6.

Table 6: Students' awareness about metacognitive strategies

\begin{tabular}{|l|l|l|l|}
\hline $\begin{array}{l}\text { S. } \\
\text { No. }\end{array}$ & Themes & Frequency & Average \\
\hline $\mathbf{1}$ & Little bit awareness about metacognitive strategies. & $\mathbf{2 5}$ & $\mathbf{2} \%$ \\
\hline $\mathbf{2}$ & Students having no awareness. & 63 & $6 \%$ \\
\hline $\mathbf{3}$ & Students providing no comments. & $\mathbf{2 5}$ & $\mathbf{2} \%$ \\
\hline
\end{tabular}

Table 6 revealed that $2 \%$ university students having little bit awareness about different learning strategies, means they are not fully aware of strategies. Remaining 2\% students did not provide any comments and 6\% students have no awareness about different metacognitive strategies. It means that most of university students are not fully aware of different learning strategies, its benefit and uses in the improvement of their learning process. 


\section{Discussion}

This study found that using notes provided by teacher is highly used metacognitive strategy by university student. The finding is in alignment with that of Sawhney and Bansal (2015), as they concluded that majority of university students frequently read and use notes. This study found that highlighting is highly used but underlining is moderately used learning strategy. The study of Dunlosky, Rawson, Marsh, Nathan and Willingham (2013) also found the similar results by rating highlighting strategy and giving low utility to underlining strategy. This study concluded self-questioning is moderately used learning strategy, this finding is supported by Sawhney and Bansal (2015), as they found comparatively few students use self-testing while studying. This study concluded that summarization, note taking, taking of main idea and concept mapping are highly used metacognitive strategies. This finding is supported by studies of Woolfolk (2013) and Slavin (2009), as both of them also described most common strategies of metacognition used by university students were found to be summarizing, note taking, taking main idea and concept mapping.

This study concluded that majority of the university students claimed that use metacognitive of strategies improved their learning process. In similar, previous research studies conducted by Gok (2010), Knox (2017), and Lai (2011), revealed proper use of different metacognitive strategies helps students to guide or direct their intellectual processes efficiently on right track to achieve their goals and solve study problems to enhance their learning process. By using the metacognitive strategies, learner enable to activate and improve their thinking towards higher level of learning.

\section{Conclusions and Recommendations}

The following six conclusions were drawn from the results of the study. First, it was concluded that summarization, highlighting, note taking, bulleting and the concept mapping are the most frequently used learning strategies by university students. Second, this research study revealed that the underlining, making outline, use of examples, dictionary and internet, self-questioning, paraphrasing and making heading and points are moderately used cognitive learning strategies by students. Third, it was concluded that group learning, discussion and book reading are least used metacognitive strategies by university students. It is, therefore, recommended for teachers to create awareness about the use and importance of these strategies among students.

Fourth, this study found that nearly half of the students are not using metacognitive strategies in their learning process. Fifth, while examining the extent to use metacognitive strategies, it was found that most of the students use them during exams, quizzes and tests. It is, therefore, recommended for teachers the to promote the frequent use of metacognitive strategies among university students. Sixth, majority of the university students claimed that use of metacognitive strategies improved their learning process. Finally, it was also found that majority of university students were not using metacognitive strategies. It is, therefore, recommended that seminars should be arranged to create awareness among students about the use, benefits and importance of metacognitive strategies to improve their learning process. Finally, it was revealed that some students were either not fully aware of the metacognitive strategies or were not totally aware of these strategies, even at university level. It, therefore, is recommended for policy makers to create modules for creating awareness among teachers and students about the metacognitive strategies at university level, and their potential benefits.

\section{References}

Almasi, J. F. (2003). Teaching strategic process in reading. New York, NY: The Guilford.

Anderson, N. (1991). Individual differences in strategy use in second language reading and testing. Modern Language Journal, 75, 460-472 
Azevedo, R., \& Aleven, V. A. W. M. M. (2013). International handbook of metacognition and learning technologies. New York, NY: Springer.

Boekaerts, M. (1999). Self-regulated learning: Where we are today. International journal of educational research, 31(6), 445-457.

Chutichaiwirath, K., \& Sitthitikul, P. (2017). The metacognitive awareness of reading strategies in Thai EFL learners. Journal of Nusantara Studies (JONUS), 2(2), 1-14.

Derry, S. J. (1992). Metacognitive models of learning and instructional systems design. In Adaptive learning environments (pp. 257-286). Springer, Berlin, Heidelberg.

Desoete, A., \& Veenman, M. V. J. (2006). Metacognition in mathematics: Critical issues on nature, theory, assessment and treatment. In Metacognition in mathematics education (pp. 1 - 10). New York: Nova Science Publishers.

Downe-Wamboldt, B. (1992). Content analysis: method, applications, and issues. Health care for women international, 13(3), 313-321.

Dunlosky, J., Rawson, K. A., Marsh, E. J., Nathan, M. J., \& Willingham, D. T. (2013). Improving students' learning with effective learning techniques: Promising directions from cognitive and educational psychology. Psychological Science in the Public Interest, 14(1), 4-58.

Efklides, A. (2011). Interactions of metacognition with motivation and affect in self-regulated learning: The MASRL model. Educational Psychologist, 46, 6-25.

Gama, C. (2000). Metacognitive awareness: a pilot study in a software design course. Cognitive Science Research Paper-University of Sussex CSRP, 91-94.

Gok, T. (2010). The general assessment of problem-solving processes in physics education. Eurasian Journal of Physics and Chemistry Education, 2(2), 110-122.

Hacker, D. J., Keener M. C., \& Kircher J. C. (2009). Writing is applied metacognition. In Hacker D. J., Dunlosky J., Graesser A. C. (Eds.), Handbook of metacognition in education (pp. 154-172). New York: Routledge.

Herrera, S. G., Holmes, M., \& Kavimandan, S. (2011). Crossing the vocabulary bridge: Differentiated strategies for diverse secondary classrooms. New York: Teachers College Press.

Hsieh, H. F., \& Shannon, S.E. (2005). Three approaches to qualitative content analysis. Qualitative Health Research, 15(9), 1277-1288.

Hunt, A. N. (2006). Metacognition and Learning Strategies for Teachers using Computers. American Review.

Johnson, D., \& Johnson, R. (2002). Learning together and alone: Overview and meta-analysis. Asia Pacific Journal of Education, 22, 95-105.

Killen, R. (2000). Outcomes-based education: Principles and possibilities. Unpublished manuscript, University of Newcastle, faculty of education.

Knox, H. (2017). Using writing strategies in math to increase metacognitive skills for the gifted learner. Gifted Child Today, 40(1), 43-47.

Krippendorff, K. (2004). Content analysis: An introduction to its methodology. Thousand Oaks. Calif.: Sage.

Kuhn, D. \& Dean, D. (2004). A bridge between cognitive psychology and educational practice. Theory into Practice, 43(4), 268-273.

Lai, E. R. (2011). Metacognition: A literature review. Always learning: Pearson research report, 24.

Martinez, M. (2006). What is metacognition? [Electronic version]. Phi Delta Kappan, 87.9, 5.

McCormick, C. B. (2003). Metacognition and Learning. In W. Reynolds, M. Weiner, GE Miller, Handbook of Psychology, pp. 79-102. Hoboken, New Jersey: John Wiley \& Sons, Inc.

Novak, J. D. (2010). Learning, creating, and using knowledge: Concept maps as facilitative tools in schools and corporations. Routledge. 8(2), 51-53. 
O’Neil Jr, H. F. \& Brown, R. S. (1997). Differential effects of question formats in math assessment on metacognition and affect. Los Angeles: CRESST-CSE University of California.

O'Malley, J. M., \& Chamot, A. U. (1990). Learning Strategies in Second Language Acquisition. Cambridge, U.K.: Cambridge University Press.

Ormrod, J.E. (1999). Human Learning (3rd Ed.). Upper Saddle River, NJ: Prentice-Hall.

Papaleontiou-Louca, E. (2014). Metacognition. In D. Phillips (ed.), Encyclopedia of Educational Theory and philosophy. (pp. 523-526). Thousand Oaks, CA: Sage Publications, Inc.

Rubin, J. (2005). The Expert Language Learner: A Review of Good Language Learner Studies and Learner Strategies. In K Johnson, Expertise in Second Language Learning and Teaching, pp. 37-63. New York, MacMillan.

Sawhney, N., \& Bansal, S. (2015). Metacognitive awareness of undergraduate students in relation to their academic achievement. The International Journal of Indian Psychology, 3(1), 107-114.

Schoenfeld, A. H. (1992). Learning to think mathematically: problem solving, metacognition, and sensemaking in mathematics. Handbook for Research on Mathematics Teaching and Learning (D. Grouws, Ed.). New York: MacMillan.

Seyf. A. (2007). Developing Psychology (Education and Learning Psychology). Tehran.Fifth Edition. Agah Publication.

Slavin, R. E. (2009). Educational psychology: Theory and practice. New Jersey: Pearson Education, Inc.

Smith, K. S., Rook, J. E., Smith, T. W., (2007). Increasing student engagement using effective and metacognitive writing strategies in content areas. [Electronic version]. Preventing School Failure. $51343-48$.

Somuncuoglu, Y., \& Yildirim, A. (1999). The relationship between achievement goal orientations and the use of learning strategies. The Journal of Educational Research, 92(5), 267-277.

Spörer, N., \& Brunstein, J. C. (2006). Erfassung selbstregulierten Lernens mit Selbstberichtsverfahren: Ein Überblick zum Stand der Forschung. Zeitschrift für pädagogische Psychologie, 20(3), 147-16o.

Sukarnan. (2005). Psikologi kognitif (Psychology of Cognitive). Surabaya, Indonesia: Srikandi.

Veenman, V. J K., Van Hout-Wolters, B. \& Afflerbach, P. (2006). Metacognition and learning: Conceptual and methodological considerations. Metacognition and Learning, 1 3-14.

Woolfolk, A. (2013). Educational psychology. (2oth ed.). New Jersey: Pearson Education Inc.

Zareei, A. (2007). The relationship between cognitive and meta-cognitive strategy use and EFL reading achievement. 